\title{
Factors associated with the nurses' intent to stay in China, Japan, and Korea: an integrative review
}

Original article

Ting Xuea, Wen-Bin Jiang ${ }^{b}$, Meng-Di Ma ${ }^{a}$, Jie Zhang ${ }^{c}$, Ming-Hui Lud ${ }^{d}$ Yong-Mei Jiang ${ }^{b, *}$

aSchool of Nursing, Qingdao University, Qingdao, Shandong 266021, China

${ }^{b}$ Nursing Department, The Affiliated Hospital of Qingdao University, Qingdao, Shandong 266000, China

cEmergency Department, Qilu Hospital of Shandong University (Qingdao), Qingdao, Shandong 266035, China

IIntensive Care Unit, Tianjin Medical University General Hospital Airport Hospital, Tianjin, 300300, China

Received: 25 December 2019; Accepted: 11 February 2020; Published: 20 September 2020

Abstract: Objective: Nurse's dimission and attrition are globally considered as a public health issue. However, few studies have focused on the nurse shortage from the perspective of intent to stay, as previous studies have focused only on why they left. The purpose of this study was to conduct an integrative review of the factors connected with why nurses in China, Japan, and Korea stay in their current workplace.

Methods: The review was done using three databases namely CNKI, Wanfang, and Web of science. The relevant studies published by Chinese, Japanese, and Koreans from 2010 were also included in this review. Literature screening and data extraction were performed by the two researchers, and the qualitative research methods were used for analysis.

Results: A total of 17 studies were analyzed in this review and of these two were qualitative and 15 were quantitative. Three themes and six sub-themes emerged from the synthesization of the data of 17 studies, which will help us to find the factors for nurses' intent to stay. The three aspects such as professional characteristics, nurses' individual characteristics, and organizational factors are the main contributing factors of nurses' intent to stay.

Conclusions: This integrated review has thrown some important factors about nurses' intent to stay. It is increasingly clear that when (1) nurses have a good professional status, (2) nurses could enjoy a good working relationship, (3) the workplace could meet the needs of personal development, and (4) nurses have good organizational support and excellent leaders, they are inclined to stay in their current jobs. Managers need to adopt targeted measures to improve nurses' intent to stay and to provide a practical reference for health care institutions and managers in different countries and areas to increase the retention rate of nurses and to alleviate the current situation of nurse shortage.

Keywords: nurse $\bullet$ intent to stay $\bullet$ China $\bullet$ Japan $\bullet$ Korea $\bullet$ nursing management $\bullet$ nurse shortage

(c) Shanxi Medical Periodical Press.

How to cite this article: Xue T, Jiang WB, Ma MD, Zhang J, Lu MH, Jiang YM. Factors associated with the nurses' intent to stay in China, Japan, and Korea: an integrative review. Front Nurs. 2020;3:269-278.

* Corresponding author.

E-mail: jymqyfy@163.com (Y.-M. Jiang).

O Open Access. ๑ 2020 Xue et al., published by Sciendo. (c) BY-NC-ND This work is licensed under the Creative Commons Attribution NonCommercial-NoDerivatives 4.0 License. 


\section{Introduction}

At present, the shortage of nurses has been recognized as a global public health issue. World Health Organization (WHO) has been concerned about this issue for a long time, and despite adopting some measures, the retention of nurses still gives a lot of headache to the international community. Especially with the aging world population and with an increasing trend in age-related chronic diseases, more and more people need to be cared for by paramedics, which means plenty of nurses are needed. This also calls for urgent attention to solve this problem globally. Cowden ${ }^{1}$ pointed out that retaining nurses in the current position is one way to minimize the impact of nursing shortage. Nurses' intent to stay refers to the intention to continue working in the same hospital with the advancement in their career development. $^{2}$ It was studied that intent to stay could be used as an important and effective index in the study of actual employee retention behavior. ${ }^{1}$ Apart from its accurate indication in nurses' actual occupational values, the study of nurses' intent to stay can provide the basis for managers to build a nursing team with strong stability and excellent service. Therefore, raising the nurse retention rate is an important way to minimize the impact of nurse shortage in the present situation.

China, Japan, and South Korea are all coastal countries located in the east of Asia. Geographically, they are close neighbors with similar historical backgrounds and cultures. As these countries have a booming economy and a growing aging population affected by age-old diseases, there is not only shortage in labor but also a heavy demand for nurses. Further, available data have shown that nurses' turnover rate was similar in these three countries.

As of 2018, the number of registered nurses per 1,000 population was only 3 according to the national bureau of statistics. ${ }^{3}$ However, as per the target set in the "Healthy China" program (2030), the number of registered nurses (per 1,000 population) should reach 4.7 by the year 2030 . Wan et al. ${ }^{4}$ conducted a survey on 778 well-experienced nurses in seven hospitals, and the results showed that $35.9 \%$ of experienced nurses had a high intention to quit their job. Zhang et al. ${ }^{5}$ tracked 343 newly graduated nurses and found that $71.8 \%$ of them wanted to resign within 1 year. This indicates that both senior nurses and junior nurses have a high turnover intention. This shows that China is facing the potential loss of human resources in nursing.

Until 2018, the number of registered nurses in Japan has been increasing constantly. ${ }^{6}$ However, over the past 5 years, the turnover rate of full-time nurses in Japan remained roughly $11 \% .^{7}$ In addition, Japan's population growth under 18 years shows a downward trend, which means it is getting harder for managers to recruit new graduate nurses, ${ }^{7}$ and how to reduce nurses' turnover rate also demands a prompt solution. Besides, the number of nurses per 1,000 population in South Korea has been continuously growing in recent years, and rose to 6.97 in $2017,{ }^{8}$ but was still below the average level of 9.0 per 1,000 population. ${ }^{9}$ Although the government has taken some measures to deal with this problem, the numbers of nursing personnel are inadequate to deal with the aging population situation. ${ }^{8}$

Therefore, it is necessary to learn about the influencing factors of nurses' retention to stay in these three countries. To our knowledge, several studies have been carried out in these three countries, which have explored the factors that encourage nurses to stay in their current profession and jobs, but these findings lack the comprehensive summary and induction. The points for this review, therefore, were to understand the factors clearly why nurses intent to stay in their current workplace in China, Japan, and South Korea. This article reports a synthesis of the literature on this topic, and some valuable perspectives were found, which likely encourage nurses to remain in their current clinical practice. In addition, as these countries have more or less same ethnicity, we selected these three countries to exclude heterogeneity in this study, and also to provide further ideas for nursing managers in east Asia to lay out specific strategies in reversing the situation and increasing the in-service rate.

\section{Methods}

\subsection{Inclusion criteria}

The inclusion criteria included the literature published since 2010 that explicitly discussed nurses' intent to stay and its influential factors. In addition, all the literature from China, Japan, and South Korea were included. This study used different types of studies, such as cross-sectional, cohort, and case-control studies, and included opinion articles, news reports, commentaries, conference articles, and data compilation. The literature review was not included. Chinese, English, Korean, and Japanese literature were included in this study as each country has a different national language.

\subsection{Search strategy}

The purpose of the search strategy was to find published studies related to the topic of nurses' intent to stay. In the process of literature retrieval, we used the quantitative PICO criteria (see Table 1). And then we searched for the literature in the following three databases namely Wanfang, CNKI, and Web of Science from March 2019 to May 2019. The whole process was carried out by 


\begin{tabular}{llll}
\hline Population & Intervention & Comparison & Outcome \\
\hline \hline Nurse & Nil & Nil & Intent to stay \\
Paramedic & & & Retention intention \\
Registered nurse & & & \\
\hline
\end{tabular}

Table 1. Qualitative PICO criteria: What factors are associated with retention of nurses in the current workforce?.

two researchers and they searched intensively using the individual text words in the search strings and the Boolean operators AND and OR to retrieve only relevant literature for quality appraisal. Two search terms related to "nurse" and "intent to stay" were used as thesaurus words or keywords to search the database of Wanfang, CNKI, and Web of Science. Taking Web of Science database as an example, the specific retrieval formula used is "TS = nurse AND TS = intent" to stay AND PY $=(2010-2019)$ ". All the literature in this study have come from online electronic journals. References that have been included in the literature were tracked down, and relevant experts and literature's corresponding authors were contacted to obtain relevant information that was not found in the above search.

\subsection{Quality appraisal}

Adhering to the Australian JBI evidence-based health care center (2008) quality evaluation criteria for descriptive papers, the papers' design scheme, papers' quality control, and appropriateness of findings were assessed in the integrative review. ${ }^{10}$ All papers were examined by two researchers and consensus agreement reached about whether the literature should be included or not in the data extraction stage.

\subsection{Data extraction}

According to the requirements of the data extraction table, the data information extracted by the two researchers independently were included in the study and they are (1) basic information of literature, including title, author, year of publication, journal of publication, etc.; (2) research object content, including area, sample size, etc.; (3) study methods, including investigative tools, research design, research indicators, etc.; and (4) main results and conclusions.

\subsection{Analysis method}

This study adopts a qualitative analysis method to summarize and describe the information and results included in the literature. The main content includes the basic information of the research literature and the classification and induction results of influencing factors.

\section{Results}

\subsection{Information of literature}

Seventeen articles were included in this study, including 15 cross-sectional studies and 2 qualitative studies. Seven studies were from China, seven studies were from Japan, and three studies were from South Korea. The specific screening process and results are shown in Figure 1 and basic information on included studies is shown in Table 2.

\subsection{Assessment tools for nurses' intent to stay in the three countries}

Most of the studies on nurses' intent to stay were conducted by questionnaires. Different versions of the measurement tools are used in different countries. In 1998, Turnley et al. ${ }^{11}$ used the turnover intention scale and the job-hunting behavior scale to evaluate employees' intent to stay. Based on the scale and the national conditions of China, the Chinese version of the scale was used by Tao Hong and Wang, ${ }^{12}$ which consists of 6 items and uses Likert 5-level scoring method, with the Cronbach's $\alpha$ being 0.766. In addition, the Chinese version of the Hill retention scale ${ }^{13}$ was used in a study of Taiwan ${ }^{14}$ to assess the nurses' intent to stay, which included 12 items and used the Likert 7-level scoring method, with the Cronbach's $\alpha$ being 0.88 . In Japan, a study ${ }^{15}$ adopted the turnover intention scale presented by Maertz and Boyar ${ }^{16}$ to evaluate the protective factors affecting nurses' retention intention. This scale included four items, with the Cronbach's $\alpha$ over 0.9. In 2013, Ja et al. ${ }^{17}$ worked out the South Korean version of turnover intention scale, which was composed of three dimensions of evaluation criteria: job satisfaction, job performance, and interpersonal relationship, with 10 items in total and Cronbach's $\alpha$ value 0.831 .This provides a reference for the study of South Korea's intent of the nurses to stay.

In general, due to regional and cultural differences, different countries have developed research tools with different standards in line with their national conditions, so each area can continue to improve the accuracy and reliability of the measuring tools according to the specific conditions, so as to predict the nurses' intent to stay better and substantially improve the retention rate.

\subsection{The contributing factors of nurses' intent to stay}

\subsubsection{Professional characteristic}

Professional characteristic is a comprehensive reflection of the internal and external performances of the occupational 


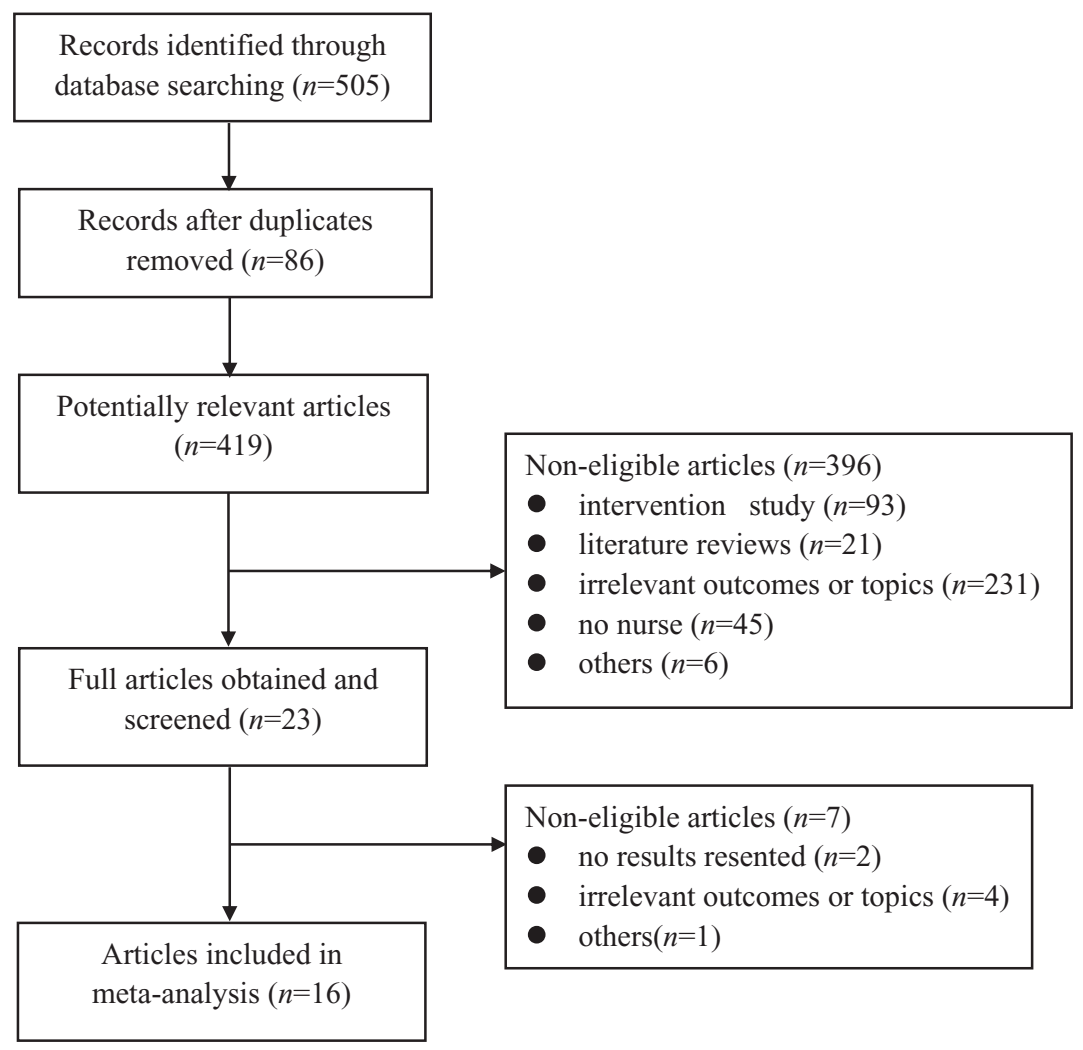

Figure 1. Screening flow diagram.

group. This paper will further elaborate the influences of professional social status and job characteristics.

\subsubsection{Professional social status}

Professional social status is the degree of respect that the professional group receives in the society, mainly reflected in the value of the nursing work. In China, influenced by traditional concepts, nurses do not have a high sense of value. Chen ${ }^{18}$ pointed that the more value the nursing work has, the stronger the intention to stay. Similar results were also found in Japan. ${ }^{19}$ In South Korea, nursing is female-dominated occupations traditionally, and due to the influence of national policies, male nurses who have served in the military for 2 years are less willing to retain their posts because their experience and professional social status are lower than female peers. ${ }^{20}$ Therefore, as for an intermediary factor, professional social status can influence the nurses' sense of work value, thus playing a powerful a role in nurses' willingness to retain their posts.

\subsubsection{Job characteristics}

Nursing is a profession that requires both intelligence and strength. With the transformation of biomedical social model, the role of modern clinical nursing has also changed. The nursing shortage has not been effectively improved, and the number of patients is going on increasing in China, Japan, and South Korea. As a consequence, the in-service clinical nurses have to suffer excessive workload and tremendous professional pressure, which easily leads to nurses' mood disorders with potential gastrointestinal, cardiovascular dysfunction, poor sleep, or even worse, with the tendency of getting depression. ${ }^{21-23}$ In addition, the complexity of role functions hinders nurses from making role transition, and likely causes role maladjustment or change in roles, which is mostly found among new nurse group. The studies in the three countries showed that role maladjustment or adaption is one of the most significant reasons for new nurses' low intent to stay. ${ }^{24-26}$

At the same time, occupational risk is also one of the significant factors affecting the nursing staff's intent to stay. Nurses are the high-risk group, suffering occupational injury and occupational exposure. Wang et al. ${ }^{27}$ pointed out that the prevalence rate of low back pain among nurses increased with the work intensity. A study in Japan also showed that the more frequently nurses shift their work, the easier they would suffer from work shift disorder. ${ }^{28}$ Furthermore, the workplace violence 


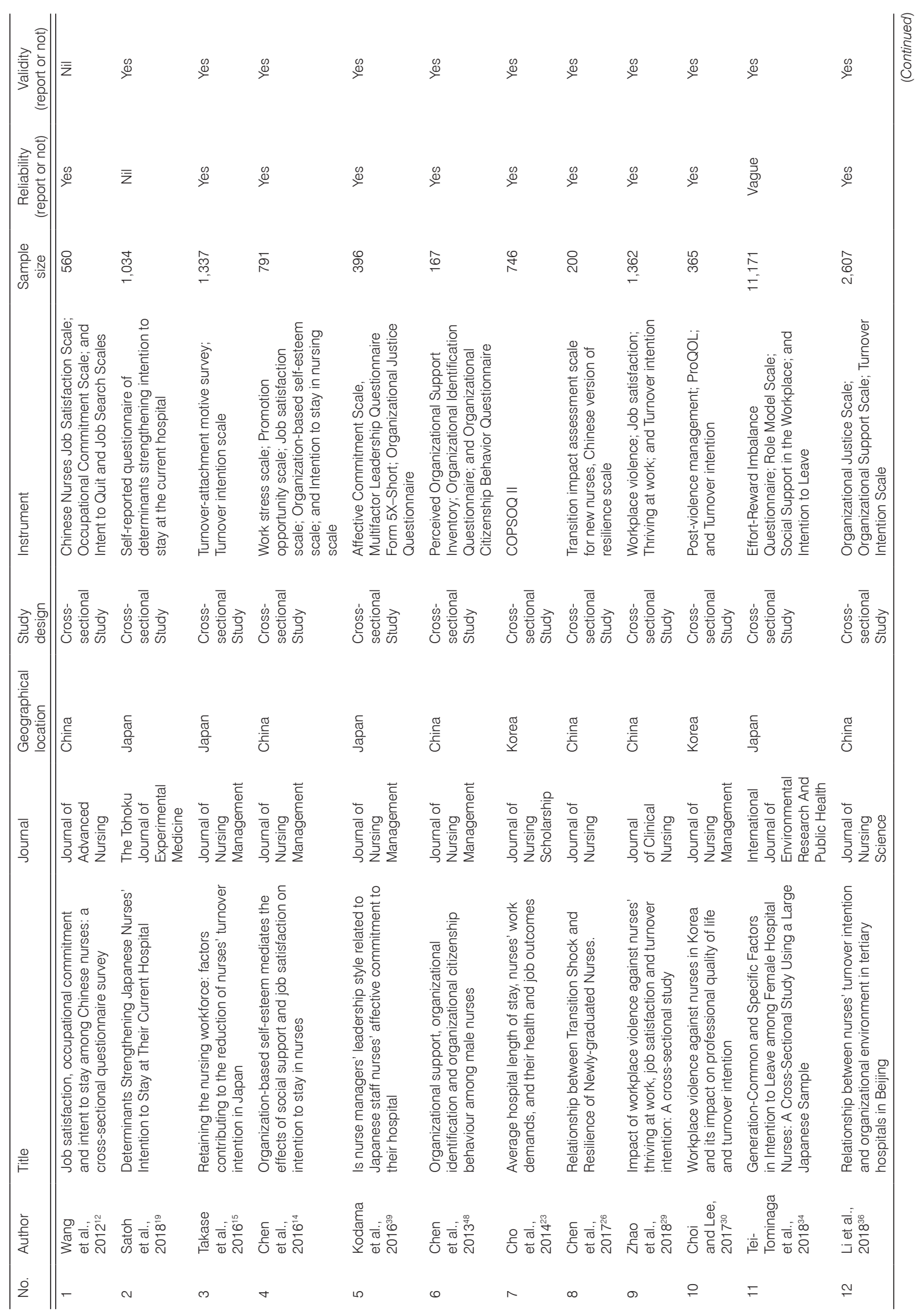




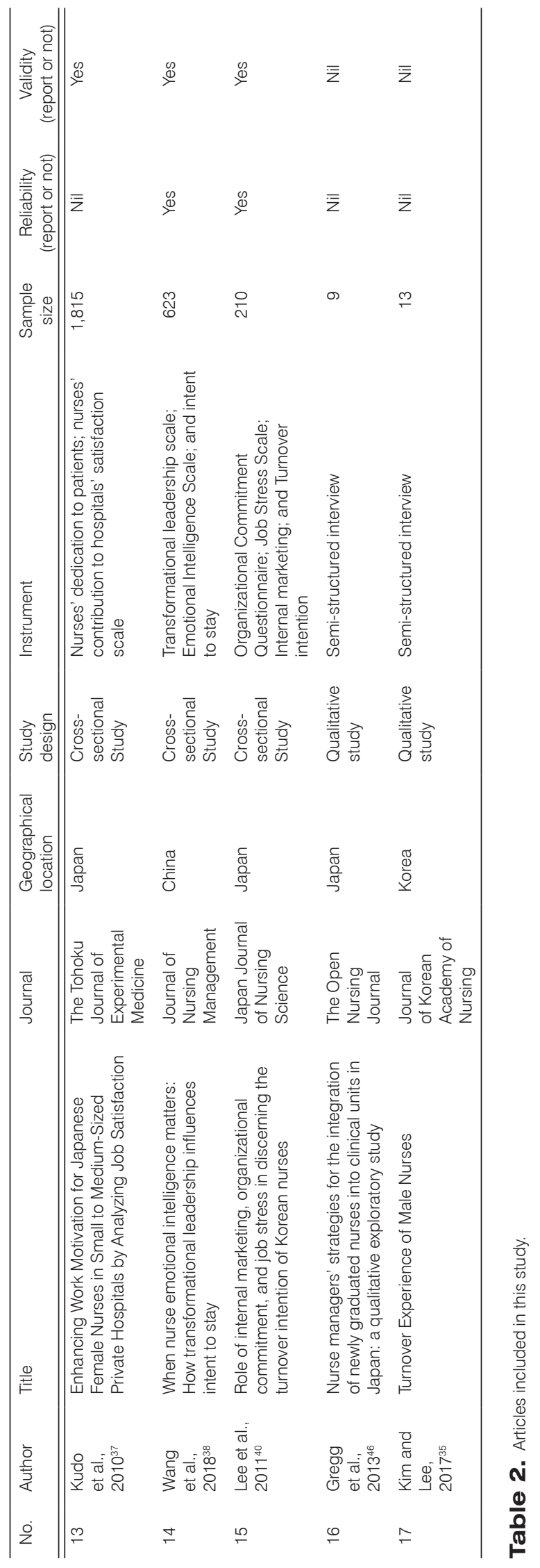

reduces nurses' job satisfaction and quality of life and stimulates nurses' negative emotions, thus lessening nurses' intent to stay, ${ }^{29}$ which is consistent with the research results of Choi et al. ${ }^{30}$ in South Korea.

Thus, nursing occupational security and its occupational adaptability have become the primary factor affecting nurses' physical and mental health. Nursing managers and scientific researchers should pay more attention on nurses' occupational health, actively explore and implement measures to improve nurses' occupational safety and help nurses adapt to the complex professional roles as soon as possible, in order to achieve the transformation of their professional roles and to improve the quality of nursing career and the retention rate.

\subsubsection{Nurses' characteristics}

\subsubsection{Demographic factor}

Personal characteristics cannot be ignored when exploring measures of intent to stay. Many studies ${ }^{31-34}$ have shown that nurses' age, gender, work experience, and other demographic factors are closely related to nurses' intent to stay. Wang et al. ${ }^{32}$ confirmed that a strong positive correlation exists between nurses' age, job position, and intent to stay. A South Korean study ${ }^{33}$ showed that nurses with $>6$ years experience got higher scores than those with $<6$ years experience. A Japanese study ${ }^{34}$ divided nurses into different groups according to age, and the results showed that nurses of different ages and backgrounds also made difference on their intent to stay. Besides, gender also has an influence on the intent to stay ${ }^{19}$. Therefore, the nursing managers should lay stress on nurses' individuality, physical and psychological necessities, optimize the structure of the nursing organization. At the same time, they should be given full pay to the ability of "reasonable employment, good at employing."

\subsubsection{Professional satisfaction}

Professional satisfaction is judged by nurses as a measure of contentedness resulting from the integration of their needs to their current job and personal requirements, and it will get reflected in job satisfaction, identity, loyalty, work expectation, and so on. Wang et al. believed that nurses' job satisfaction and occupational commitment were significantly correlated with their intent to stay. ${ }^{32}$ Nurses' career satisfaction will affect their working conditions. According to the research of Kim et al. ${ }^{35}$ from South Korea, for every one point reduction in job and organization satisfaction, nurses' turnover risk will increase by 1.4 times. A large-sample survey in 
Japan $^{34}$ showed that nurses with strong values, strong professional ethics, and high professional commitment have the highest intent to stay.

Job satisfaction reveals nurses' expectation and attitude, and the higher the job satisfaction is, the better the nurses' professional identity will be. So with a high job satisfaction, it will be much easier for nurses to obtain the sense of achievement, to get their expectations fulfilled, and to be more loyal to their team and more willing to stay. It is suggested that the managers should promote restructuring on nursing work, pay attention to nurses' work necessities and career planning in order to bring their potential into full play and improve their career satisfaction.

\subsubsection{Organizational factor}

\subsubsection{Organization environment}

Organization environment refers to the factors or forces that can interfere in the potential operation and performance of an organization, including work environment, organizational atmosphere, organizational support, and commitment and fairness. The organization environment plays a decisive role in the survival and development of an organization and is also an essential factor affecting the retention of members. Domestic researches have shown that organizational support and justice, as an important part of the organizational environment, are the protective factors for nurses' intent to stay. ${ }^{36}$ This is consistent with the findings of Park et al. ${ }^{33}$ In Japan, Kudo et al. ${ }^{37}$ investigated 2,249 nurses in small- and medium-sized hospitals and found that nurses' working conditions, relationship with the organization, good welfare system, and the access to nursing education are significantly correlated with nurses' contribution to the hospital.

Organizational environment is an essential link in making sure the normal operation of a hospital and also a positive predictor of nurses' intent to stay. Therefore, managers should actively create a good organizational environment, introduce advanced equipment and facilities, create a friendly, fair, and positive workplace atmosphere, and stimulate nurses' working motivation and enthusiasm.

\subsubsection{Leadership factor}

Nursing leaders are the important driving force behind professional nursing development and the core force of nursing team. The leadership role of nursing managers is of great significance to the cohesion of the team, and the leadership style is the main embodiment of leadership. Wang et al. ${ }^{38}$ showed that the transformational leadership style was positively correlated with nurses' intent to stay. Japanese researcher Kodama $^{39}$ further analyzed the components of the transformational leadership style and found that the intellectual stimulation factor in the transformational leadership style was an important factor to enhance nurses' emotional commitment to the organization and their willingness to retain their posts. In addition, South Korean researcher Lee et al. ${ }^{40}$ found that the management philosophy of a leader has a distinct effect on the overall working atmosphere and the team relations, and leaders' ability of communication and coordination are considered to be indispensable for increasing nurses' intent to stay and their job satisfaction. $^{41}$

\section{Discussion}

The purpose of this article is to identify the factors that affect nurses' intent to stay on the job through a comprehensive assessment of the published literature. Seventeen articles were included in this study, from which we extracted three categories and seven sub-categories. It is becoming increasingly clear that when nurses have a good professional status, could enjoy a good working relationship, and if the workplace could meet the needs of personal development with good organizational support and excellent leaders, they are inclined to stay in their current jobs. What's more, improving their resilience seems to help nurses get through the adjustment phase better.

In view of these factors, some strategies to solve the shortage of nurses have been put forward in recent years. From the national perspective, China, Japan, and South Korea have put forward their solutions to deal with the shortage of nurses in order to cope with the aging population having their social problems getting aggravated each and every day. Nursing managers and researchers in these countries are actively exploring the measurement tools of nurses' intent to stay, and the relevant contributing factors and some intervention measures have been taken based on the known factors.

In China, short-term focused treatment technology in group counseling, ${ }^{42}$ working pressure management mode for nurses ${ }^{43}$ and magnetic nursing workplace ${ }^{44}$ were used to improve nurses' intent to stay and obtained good results. In Japan, researchers improved the nurses' retention intention by carrying out career planning programs and building a colleague support system. ${ }^{45,46}$ Meanwhile, in South Korea, Kang ${ }^{47}$ applied cognitive behavior therapy help nurses to improve the ability to cope with work, so as to enhance nurses' intent to stay. Kim et al. ${ }^{42}$ showed that the stability of the 
nursing team could be improved by training the leaders in their operational capability and skills.

To sum up, as a clinical front-line staff, the special professional characteristics determine that nurses often have to face various psychological pressure and sense of insecurity. At the same time, high professional values, high professional identity, and the sense of belonging can make nurses' to be more loyal to their job. Therefore, hospital managers, educators, and decision makers can take comprehensive measures from the aspects of nurses, organizations and leaders can find new ideas and methods for improving nurses' intent to stay in a multi-tiered and broad-field manner, not only by offering training lessons for nurses but also for leaders. The training programs can effectively deepen the communication between leaders and team members, improve nurses' practicing environment, relieve their work pressure, and improve their sense of belonging in the team.

\section{Conclusions}

As the concept of health continues to evolve, nurses are needed now more than ever, and the difficulties faced in their recruitment and retention are now a serious problem. If not addressed, it will affect the nursing outcome for elderly people and hospital patients. The problem of a nurse workforce related to demographic factors must not be compounded by the failure to address the nurse's work-related needs. The findings of this review will provide a useful basis for further intervention studies on this topic. Meanwhile, based on the diverse emphases on contributing factor in different areas, managers need to adopt targeted measures to improve nurses' intent to stay and to provide practical reference for health care institutions and managers in different countries and

\section{References}

1. Cowden TL, Cummings GG. Testing a theoretical model of clinical nurses' intent to stay. Health Care Manage Rev. 2015;40:169-181.

2. Price JL. Reflections on the determinants of voluntary turnover. Int J Manpower. 2001;22:600-624.

3. National Bureau of Statistics. Statistical bulletin on national economic and social development 2018. http://www.stats.gov.cn/tjsj/zxfb/201902/t20190 228_1651265. html. Accessed June 7, 2019 (in Chinese).

4. Wan QQ, Li ZY, Zhou WJ, et al. Effects of work environment and job characteristics on the turnover intention of experienced nurses: the mediating role of work engagement. J Adv Nurs. 2018;74:1332-1341. areas to increase the retention rate of nurses and to alleviate the current situation of nurse shortage.

\section{Limitation}

While entire process was made to provide a strict quality control, there are also some limitations. First, it is likely that some articles that have not been published in electronic journals were missed. Second, only three countries' studies were included in our review, which may mean some other relevant information from other countries remains unknown. Third, due to the limitation of database retrieval from different countries, we have not been able to obtain the complete literature published in Korean and Japanese databases. Finally, although three categories and six sub-categories emerged from our integrative review to provide some views to why nurses should remain in the current job, and it cannot be said that these data represent the nursing environment as a whole. Targeting nurses' intent to stay presents another promising area for future research in coping with the global shortage of nurses. Only a few interventions have attempted to alleviate the nurse shortage from the perspective of retention intention. Considering that many interventions lack evidence-based behavioral strategies, this could be an important area for future research.

\section{Ethical approval}

Ethical issues are not involved in this paper.

\section{Conflicts of interest}

All contributing authors declare no conflicts of interest.
5. Zhang YY, Wu J, Fang Z, et al. Newly-graduated nurses' intention to leave in their first year of practice in Shanghai: a longitudinal study. Nurs Outlook. 2016;65:202-211.

6. Japanese Nursing Association. Survey on the demand and supply of hospital nurses 2017; 2018. http://www.nurse.or.jp/up_pdf/20180502103904_f. pdf. Accessed February 25, 2019 (in Japanese).

7. Satoh M, Watanabe I, Asakura K. Determinants strengthening Japanese nurses' intention to stay at their current hospital. Tohoku J Exp Med. 2018;246:175-182.

8. Hong E, Lee YS. The mediating effect of emotional intelligence between emotional labour, job stress, 
burnout and nurses' turnover intention. Int J Nurs Pract. 2016;22:625-632.

9. Organization for Economic Cooperation and Development. OECD health statistics; 2018. http:// www.oecd.org/els/health-systems/oecd-healthstatistics-2018-frequently-requested-data.htm. Accessed February 25, 2019.

10. Hu Y. Evidence-Based Nursing. Beijing: People's Medical Publishing House; 2012 (in Chinese).

11. Turnley WH, Feldman DC. Psychological contract violations during corporate restructuring. Hum Resour Manage. 1998;37:71-83.

12. Wang L, Tao H, Ellenbecker $\mathrm{CH}$, Liu XH. Job satisfaction, occupational commitment and intent to stay among Chinese nurses: a cross-sectional questionnaire survey. J Adv Nurs. 2012;68:539-549.

13. Hill KS. Work satisfaction, intent to stay, desires of nurses, and financial knowledge among bedside and advanced practice nurses. J Nurs Adm. 2011;41:211-217.

14. Chen MF, Ho CH, Lin CF, et al. Organization-based self-esteem mediates the effects of social support and job satisfaction on intention to stay in nurses. J Nurs Manage. 2016;24:88-96.

15. Takase M, Teraoka S, Yabase K. Retaining the nursing workforce: factors contributing to the reduction of nurses' turnover intention in Japan. J Nurs Manage. 2016;24:21-29.

16. Maertz CP, Boyar SL. Theory-driven development of a comprehensive turnover-attachment motive survey. Hum Resour Manage. 2012;51:71-98.

17. Ja YE, Heejeong K. Development and Testing of a Nurse Turnover Intention Scale (NTIS). J Korean Acad Nurs. 2013;43:256 (in Korean).

18. Chen LC, Perng SJ, Chang FM, et al. Influence of work values and personality traits on intent to stay among nurses at various types of hospital in Taiwan. J Nurs Manage. 2016;24:30-38.

19. Saito $Y$, Igarashi $A$, Noguchi-Watanabe $M$, et al. Work values and their association with burnout/ work engagement among nurses in long-term care hospitals. J Nurs Manage. 2018;26:393-402.

20. Kim H, Lee J. Turnover experience of male nurses. J Korean Acad Nurs. 2017;47:25-38 (in Korean).

21. Kamijo Y, Kanda K. Estimating nurses' workload using the diagnosis procedure combination in Japan. Int Nurs Rev. 2008;55:281-287.

22. Wang $X G$, Luo $Y Y$, Zhang $M$. Research on influence of shift work on nurse's physical and mental health. China Occup Med. 2017;44:505-509 (in Chinese).

23. Cho $\mathrm{SH}$, Park $\mathrm{M}$, Jeon $\mathrm{SH}$, Chang HE, Hong H-J. Average hospital length of stay, nurses' work demands, and their health and job outcomes. J Nurs Scholarsh. 2014;46:199-206.
24. Yu M, Kang KJ. Factors affecting turnover intention for new graduate nurses in three transition periods for job and work environment satisfaction. J Contin Educ Nurs. 2016;47:120-131.

25. Gregg MF, Toyomi W, Chifuyu H. Nurse managers' strategies for the integration of newly graduated nurses into clinical units in Japan: a qualitative exploratory study. Open Nurs J. 2013;7:157-164.

26. Chen M, Sun X, Zhu XP, Tian MM, Shi Y. Relationship between Transition Shock and Resilience of Newly-graduated Nurses. J Nurs (China). 2017;24:50-53 (in Chinese).

27. Wang $X L$, Ren JQ, Liu J. The status and influencing factors of low back pain of 909 nurses in three tertiary grade A hospitals. Chin Nurs Manage. 2016;16:61-64 (in Chinese).

28. Asaoka S, Aritake S, Komada Y, et al. Factors associated with shift work disorder in nurses working with rapid-rotation schedules in Japan: the nurses' sleep health project. Chronobiol Int. 2013;30:628-636.

29. Zhao SH, Shi Y, Sun ZN, et al. Impact of workplace violence against nurses' thriving at work, job satisfaction and turnover intention: a cross-sectional study. J Clin Nurs. 2018;27:2620-2632.

30. Choi S, Lee H. Workplace violence against nurses in Korea and its impact on professional quality of life and turnover intention. J Nurs Manage. 2017;25:508-518.

31. Blegen MA, Spector N, Lynn MR, Barnsteiner J, Ulrich BT. Newly licensed RN retention. J Nurs Adm. 2017;47:508-514.

32. Wang L, Tao H, Ellenbecker $\mathrm{CH}$, Liu X. Job satisfaction, occupational commitment and intent to stay among Chinese nurses: a cross-sectional questionnaire survey. J Adv Nurs. 2012;68:539-549.

33. Park S, Lee T. Factors influencing Korean nurses' intention to stay: a systematic review and metaanalysis. J Korean Acad Nurs Adm. 2018;24:139148 (in Korean).

34. Tei-Tominaga M, Asakura K, Asakura T. Generationcommon and specific factors in intention to leave among female hospital nurses: a cross-sectional study using a large Japanese sample. Int J Environ Res Public Health. 2018;15:1591.

35. Kim S, Lee K. Predictors of turnover among new nurses using multilevel survival analysis. J Korean Acad Nurs. 2016;46:733-743 (in Korean).

36. Li ZY, Zhou WJ, Liu CY, et al. Relationship between nurses' turnover intention and organizational environment in tertiary hospitals in Beijing. J Nurs Sci. 2018;33:46-49 (in Chinese).

37. Kudo Y, Kido S, Shahzad MT, Shida K, Satoh T, Aizawa $Y$. Enhancing work motivation for Japanese female nurses in small to medium-sized private 
hospitals by analyzing job satisfaction. Tohoku J Exp Med. 2010;220:237-245.

38. Wang L, Tao H, Bowers BJ, Brown R. When nurse emotional intelligence matters: How transformational leadership influences intent to stay. J Nurs Manage. 2018;26:358-365.

39. Kodama $Y$, Fukahori $H$, Sato $K$, Nishida T. Is nurse managers' leadership style related to Japanese staff nurses' affective commitment to their hospital? J Nurs Manage. 2016;24:884-892.

40. Lee H, Kim M, Yoon J. Role of internal marketing, organizational commitment, and job stress in discerning the turnover intention of Korean nurses. Jpn J Nurs Sci. 2011;8:87-94.

41. Kim MH, Yi YJ, Impact of leader-member-exchange and team-member-exchange on nurses' job satisfaction and turnover intention. Int Nurs Rev. 2019;66:242-249.

42. Zhang L, Liu XH, Kang $Y H$, Jin AL, Qu XX. Using solution-focused group counseling to improve the nurses' professional identity. Nurs J Chin People's Liberation Army. 2017;35:62-65 (in Chinese).

43. Ji GL, Zhou HX. Application of job stress management model in the nursing management in operation room. Nurs J Chin People's Liberation Army. 2016;33:51-53, 60 (in Chinese).

44. Wang Y, Zeng TY, Liu Y, et al. Construction and practice of magnetic nursing workplace. J Nurs Sci. 2019;34:52-56 (in Chinese).

45. Manaho Y, Toshio K, Yuko N. Effects of web-based career identity training for stress management among Japanese nurses: a randomized control trial. J Occup Health. 2008;50:191-193.

46. Gregg MF, Wakisaka T, Hayashi C. Nurse managers' strategies for the integration of newly graduated nurses into clinical units in Japan: a qualitative exploratory study. Open Nurs J. 2013;7:157-164.

47. Kang J, Kim J, Yun S. Effects of a cognitive rehearsal program on interpersonal relationships, workplace bullying, symptom experience, and turnover intention among nurses: a randomized controlled trial. J Korean Acad Nurs. 2017;47:689-699 (in Korean).

48. Chen SH, Yu HY, Hsu HY, Lin FC, Lou JH. Organisational support, organisational identification and organisational citizenship behaviour among male nurses. J Nurs Manag. 2013;21:1072-1082. 